A feasibility study on the expected seismic AVA signatures of deep fractured geothermal reservoirs in an intrusive basement

This content has been downloaded from IOPscience. Please scroll down to see the full text. 2014 J. Geophys. Eng. 11065008

(http://iopscience.iop.org/1742-2140/11/6/065008)

View the table of contents for this issue, or go to the journal homepage for more

Download details:

IP Address: 131.114.9.234

This content was downloaded on 07/11/2014 at $16: 36$

Please note that terms and conditions apply. 


\title{
A feasibility study on the expected seismic AVA signatures of deep fractured geothermal reservoirs in an intrusive basement
}

\author{
Mattia Aleardi and Alfredo Mazzotti \\ Earth Sciences Department, University of Pisa, Via S Maria 53, 56126 Pisa, Italy \\ E-mail: mattia.aleardi@dst.unipi.it
}

Received 21 May 2014, revised 4 September 2014

Accepted for publication 26 September 2014

Published 6 November 2014

\begin{abstract}
The deep geothermal reservoirs in the Larderello-Travale field (southern Tuscany) are found in intensively fractured portions of intrusive/metamorphic rocks. Therefore, the geothermal exploration has been in search of possible fracture signatures that could be retrieved from the analysis of geophysical data. In the present work we assess the feasibility of finding seismic markers in the pre-stack domain which may pinpoint fractured levels. Thanks to the availability of data from boreholes that ENEL GreenPower drilled in the deep intrusive basement of this geothermal field, we derived the expected amplitude versus angle (AVA) responses of the vapour reservoirs found in some intensely, but very localized, fractured volumes within the massive rocks. The information we have available limit us to build 1D elastic and isotropic models only and thus anisotropy effects related to the presence of fractures cannot be properly modelled.

We analysed the velocities and the density logs pertaining to three wells which reached five deep fractured zones in the basement. The AVA response of the fractured intervals is modelled downscaling the log data to seismic scale and comparing the analytical AVA response (computed with the Aki and Richards approximation) and the AVA extracted from a synthetic common mid point (calculated making use of a reflectivity algorithm). The results show that the amplitude of the reflections from the fractured level is characterized by negative values at vertical incidence and by decreasing absolute amplitudes with the increase of the source to receiver offset. This contrasts with many observations from hydrocarbon exploration in clastic reservoirs where gas-sand reflections often exhibit negative amplitudes at short offsets but increasing absolute amplitudes for increasing source to receiver offsets. Thereby, some common AVA attributes considered in silicoclastic lithologies would lead to erroneous fracture localization. For this reason we propose a modified AVA indicator which may highlight fracture locations in this peculiar rock type.
\end{abstract}

Keywords: Larderello-Travale, Italy, seismic AVA signature, fractured geothermal reservoir (Some figures may appear in colour only in the online journal)

\section{Introduction}

The Larderello-Travale geothermal field is located in southern Tuscany, in a region known for centuries for its mines and, more recently, for the exploitation of endogenous fluids which are localized in fracture systems inside the reservoir rocks (Casini et al 2010)

We verify whether a complex system of interconnected fractures hosting a geothermal reservoir gives rise to a distinct and discernible seismic AVA signature. To this end we 
make use of well-logs (density, $V_{\mathrm{p}}, V_{\mathrm{s}}$ ) from three wells in the Larderello-Travale area, and of synthetic seismograms computed on log-derived models.

We first focus our attention on AVA analysis, which has become an important tool for hydrocarbon prospecting and it is also used in geothermal exploration (Mazzotti et al 2002, Casini et al 2009).

However, the various AVA techniques have been mainly applied in clastic lithologies for hydrocarbon exploration (see Ostrander (1984), Rutherford and Williams (1989), Mazzotti (1990), Mazzotti (1991) and Fatti et al (1994), among others) and few examples refer to carbonate reservoirs (Adriansyah and McMechan 2001, Shen et al 2002). Therefore the AVA response of a massive intrusive rock, locally characterized by interconnected fractures, as it is the case of the deep basement rocks of the geothermal field in the Larderello-Travale area, is largely unknown.

It is well known that several combinations of petrophysical and/or lithological factors can cause similar AVA responses and thus care should be taken to associate a given response to the presence of fractures only. However, the specificity of the case we discuss here makes this inherent ambiguity of AVA interpretation much less severe. In fact, we are dealing with deep massive granites, locally affected by intense fracturing and not many lithological variables are likely to come into play.

In the following sections, after a brief recall of the AVA method derived from the Aki and Richards (1980) and from the Shuey (1985) approximations of the P-wave reflection coefficients we illustrate the available well-logs and we derive blocky models by means of the Backus averaging method (Backus 1962).

Then, for each one of the five fractured intervals within the intrusive basement we calculate the 'analytical' AVA response through the Shuey equations and the 'experimental' AVA response by measuring the amplitudes of the corresponding reflections on synthetic seismograms.

Therefore, we compare the 'analytical' and the 'experimental' AVA responses and we discuss the applicability of the AVA indicators based on the intercept (A) and gradient (B) terms of the Shuey equation, that are commonly used for hydrocarbon exploration (see, e.g. Castagna (1993), Castagna et al (1998), Ross (2000, 2002) and Ross and Sparlin (2000)), to the considered case.

Therefore the goals of this work are to verify if we can extend the linearized AVA approach to the seismic exploration of this deep fractured geothermal reservoir and, possibly, to derive a specific indicator which may help in the identification of fractured zones within massive intrusive rocks.

\section{A brief overview of the geology of the study area}

The Larderello-Travale geothermal field is located in southern Tuscany (inner Northern Apennines), where the geodynamic context is characterized by continental extensional tectonic, often linked with geothermal systems and high heat flow (Barbier 2002, Batini et al 2003). The geologic and structural characteristics of the Larderello-Travale geothermal area (Bertini et al 2006) result from the tectonic evolution of the Northern Apennine chain. More information about the geological setting of Northern Apennines and Southern Tuscany can be found in Bertini et al (2006), Carmignani and Kligfield (1990), Carmignani et al (1994, 1995), Casini et al (2010) and Jolivet et al (1990, 1998).

The wells which will be analysed in this work were drilled in the Travale area (see figure 1) where the lithostratigraphic column is composed of (from top to bottom):

- Neogene marine and continental sediments

- Ligurian Unit—flysch facies formation, mainly shales (Lower Cretaceous-Eocene)

- Tuscan Nappe-sandstones and limestones (Upper Triassic-Lower Miocene)

- Tectonic Wedge-anhydrites, quartzites and phyllites (Lower Permian-Upper Triassic)

- Metamorphic basement-phyllites and mica schists (Lower Paleozoic)

- Contact-metamorphic rocks (skarns and hornfels)

- Granitic intrusions.

The intrusive granites are the target we consider in this study.

\section{Intercept, gradient and AVA attributes}

For an idealized case of a plane wave incident on a horizontal interface separating two semi-infinite elastic and homogeneous media, Zoeppritz (1919) formulated a system of equations depending on the bulk modulus, shear modulus and density of the two semi-spaces to describe the amplitude partition of reflected and transmitted P- and S-waves. The Zoeppritz equations are so algebraically complex that many different simplified equations have been derived to intuitively grasp the physics of the reflection process. These equations are those usually used in AVA analysis and AVA inversion. For a good review of different approximations of the full Zoeppritz equations we refer the reader to Wang (1999) for higher order approximations, and to Ursenbach and Stewart (2008) for second-order approximations.

A widely used second-order approximation, valid for relatively small angles of incidence (less than $30^{\circ}$ ), is the one formulated by Shuey (1985) where the compressional-wave reflection coefficient $R_{p p}$ is approximated by an equation of the form:

$$
R_{p p}(\theta)=A+B \sin ^{2}(\theta) .
$$

In equation (1), $\theta$ is the angle of incidence, $A$ is the intercept and $B$ is the slope of the reflection coefficient.

For small perturbations in velocity and density at the reflecting interface, the intercept and slope can be approximated by

$$
A=\frac{1}{2}\left(\frac{\Delta V_{\mathrm{p}}}{\overline{V_{\mathrm{p}}}}+\frac{\Delta \rho}{\bar{\rho}}\right)
$$

and 


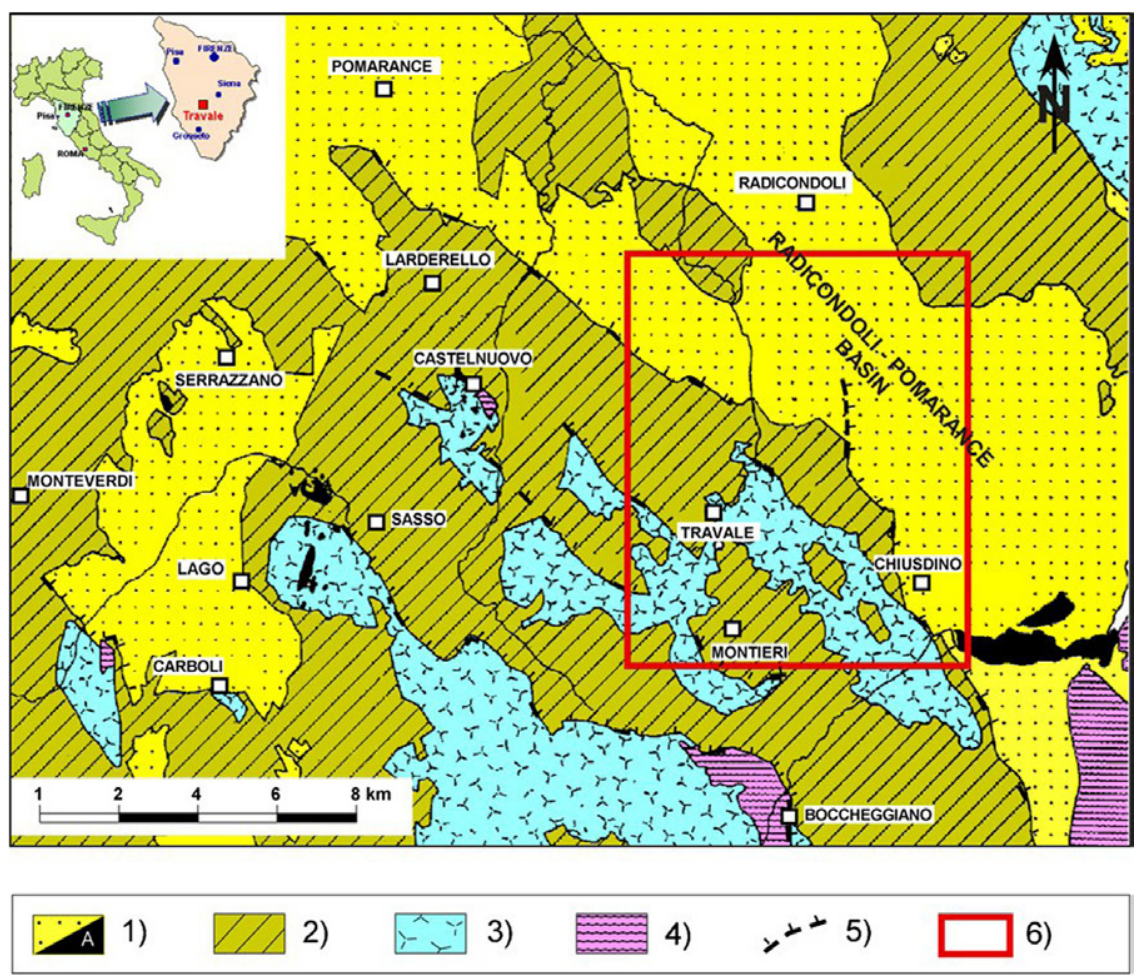

Figure 1. Location of the Travale area and schematic geological map of the Larderello-Travale field. (1) Neogene sediments (A: hydrothermal deposits); (2) flysch facies formations of the Ligurian Unit (Lower Cretaceous-Eocene); (3) sandstones and limestones of the Tuscan Nappe (Upper Triassic-Lower Miocene); (4) metamorphic basement (Paleozoic); (5) normal fault; (6) area of the Travale site where the analysed wells were drilled (from Casini et al (2010)).

$$
B=\frac{1}{2} \frac{\Delta V_{\mathrm{p}}}{\bar{V}_{\mathrm{p}}}-2\left(\frac{\overline{V_{\mathrm{s}}}}{\bar{V}_{\mathrm{p}}}\right)^{2}\left(2 \frac{\Delta V_{\mathrm{s}}}{\overline{V_{\mathrm{s}}}}+\frac{\Delta \rho}{\bar{\rho}}\right),
$$

where, at the given interface, $\Delta V_{\mathrm{p}}$ is the change in compressional velocity $\left(V_{\mathrm{p}_{2}}-V_{\mathrm{p}_{1}}\right), V_{\mathrm{p}}$ is the average compressional velocity $\left[\left(V_{\mathrm{p}_{2}}+V_{\mathrm{p}_{1}}\right) / 2\right], \Delta \rho$ is the change in density $\left(\rho_{2}-\rho_{1}\right)$, $\rho$ is the average density $\left[\left(\rho_{2}+\rho_{1}\right) / 2\right], \Delta V_{\mathrm{s}}$ is the change in shear velocity $\left(V_{\mathrm{s}_{2}}-V_{\mathrm{s}_{1}}\right)$, and $V_{\mathrm{s}}$ is the average shear velocity $\left[\left(V_{\mathrm{s}_{2}}+V_{\mathrm{s}_{1}}\right) / 2\right]$, with $V_{\mathrm{p}_{1}} ; V_{\mathrm{s}_{1}} ; \rho_{1}$ and $V_{\mathrm{p}_{2}} ; V_{\mathrm{s}_{2}} ; \rho_{2}$ being the medium properties in the first (overlying) and in the second (underlying) medium, respectively.

As shown above, the behaviour of the reflection coefficient $R_{p p}$ with increasing angle depends on contrasts in density and in compressional and shear wave velocities across the interface. According to Richards and Frasier (1976) approximation, as given in Aki and Richards (1980), we can decompose the $R_{p p}$ response into three separate terms each dependent on the contrast in $V_{\mathrm{p}}$ or $V_{\mathrm{s}}$, or $\rho$.

$R_{p p}(\Theta)=\frac{1}{2}\left(1-4 \bar{V}_{\mathrm{s}}^{2} p^{2}\right) \frac{\Delta \rho}{\bar{\rho}}+\frac{1}{2 \cos ^{2}(\Theta)} \frac{\Delta V_{\mathrm{p}}}{\bar{V}_{\mathrm{p}}}-4 \bar{V}_{\mathrm{s}}^{2} p^{2} \frac{\Delta V_{\mathrm{s}}}{\bar{V}_{\mathrm{s}}}$,

where $p$ is the ray parameter $\left(\sin \theta / V_{\mathrm{p}}\right)$.

In general, the primary attributes extracted for AVA analysis are the intercept and the gradient, which are obtained from normal move out (NMO) corrected CMP records. These attributes can be used independently, or combined to generate additional AVA attributes, and/or can be cross-plotted to pinpoint anomalous responses that may be associated with a particular lithology or pore fluid of interest.

Following the work of Rutherford and Williams (1989), Castagna and Swan (1997) separated the possible AVA responses in four classes based on the value and sign of intercept and gradient. From this classification we note that, usually, gas-sand belongs to class III, showing negative intercept and gradient. For this reason in the interpretation phase a frequently used AVA attribute is the 'stack product' $A \times B$, which is an excellent indicator for this class III gas-sands. Other attributes are the 'fluid factor' of Smith and Gidlow (1987), based on the decrease of $V_{\mathrm{p}} / V_{\mathrm{s}}$ ratio produced by gas-sands, or the reflection coefficient difference $\left(R_{\mathrm{p}}-R_{\mathrm{S}}\right)$ discussed by Castagna and Smith (1994), which highlights the decrease of P-waves reflection coefficient $\left(R_{\mathrm{p}}\right)$ and the slight increase of the $\mathrm{S}$-wave reflection coefficient $\left(R_{\mathrm{S}}\right)$ which usually occurs at an interface shale/gas-sand.

The latter attribute can be easily obtained assuming a $V_{\mathrm{p}} / V_{\mathrm{s}}=2$, and combining intercept and gradient in the following formula (Wiggins et al 1983):

$$
R_{\mathrm{p}}-R_{\mathrm{s}}=\frac{(A+B)}{2} .
$$

\section{Log-derived depth models and 'analytical' AVA responses}

Figures 2, 3 and 4 show the density, $V_{\mathrm{p}}$, and $V_{\mathrm{s}} \operatorname{logs}$ we were given after the proper calibration and editing procedure. They pertain to the three wells used in this work. Each fracture is 

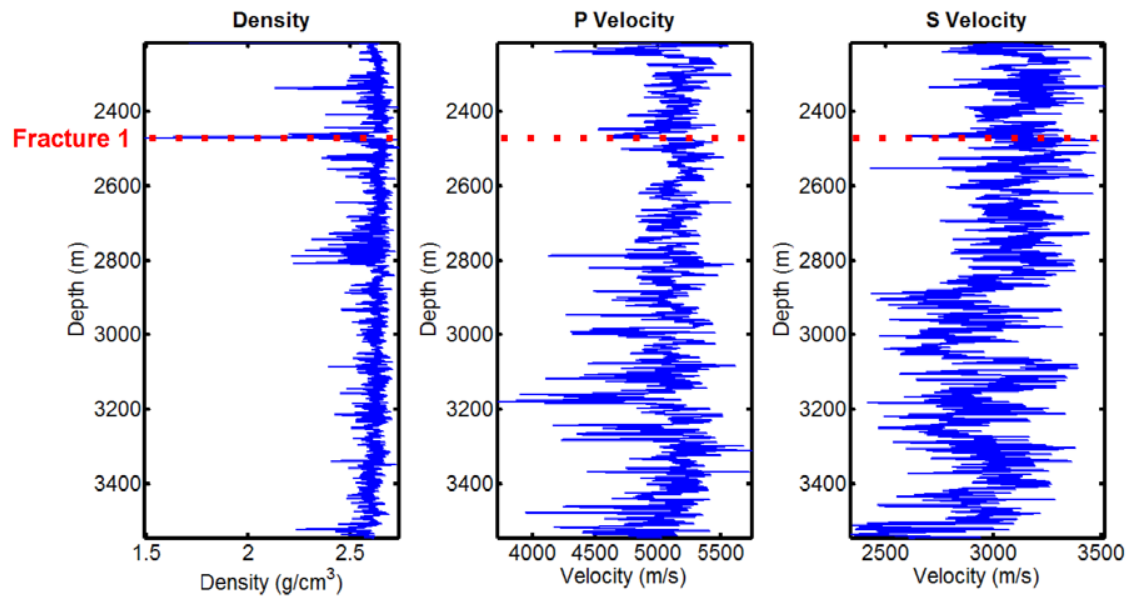

Figure 2. Density, P-wave velocity and S-wave velocity logs pertaining to well 1 . The dotted red line indicates the fracture position.
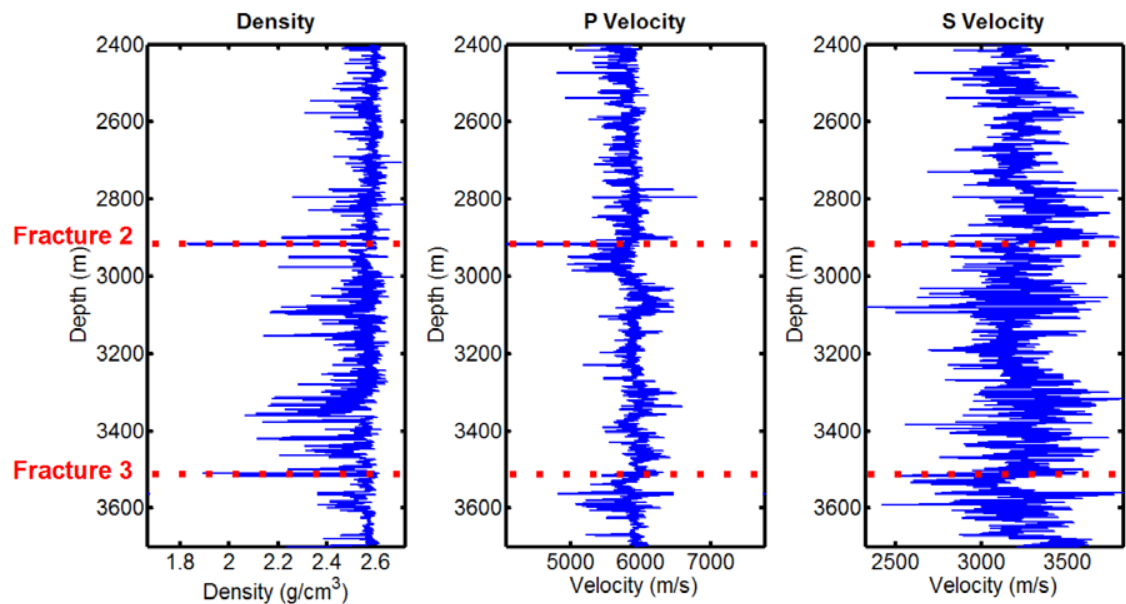

Figure 3. Density, P-wave velocity and S-wave velocity logs pertaining to well 2 . The dotted red lines indicate the fracture positions.
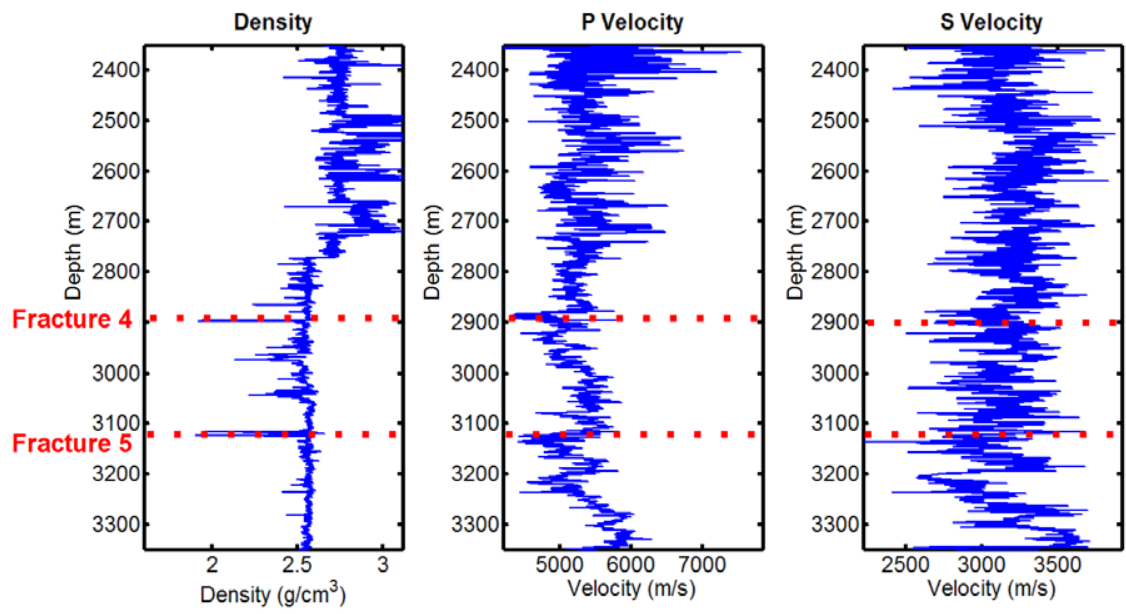

Figure 4. Density, P-wave velocity and S-wave velocity logs pertaining to well 3 . The dotted red lines indicate the fracture positions. The density decrease at $2780 \mathrm{~m}$ marks the transition between the metamorphic basement (above) and the granite rock (below).

highlighted by a dotted red line and is indicated with a number from 1 to 5. The location of each fracture was carried out by ENEL GreenPower scientists on the basis of drill stem tests, mud circulation losses and drill bit rotation/progression.
Observing these figures we can appreciate that the fractured zones produce a strong decrease of density, and also a decrease of $V_{\mathrm{p}}$ and $V_{\mathrm{s}}$. In particular, the density shows a sharp decrease that in the log appears as a spike at the fracture 

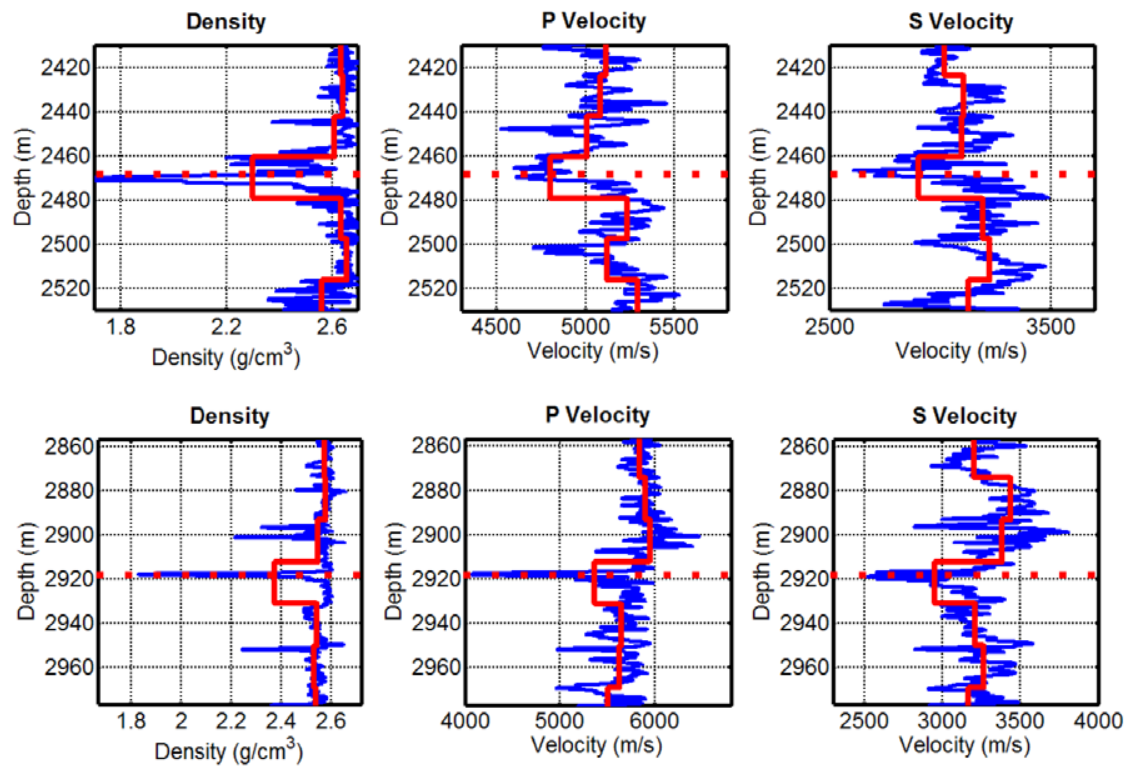

Figure 5. Close-ups of the density, P-wave velocity and S-wave velocity near fractures 1 and $2((a)$ and $(b)$, respectively). The original logs are in cyan while the blocked logs obtained with Backus averaging are in red. The dotted red lines indicate the fracture positions.

location, indicating the very small width of the fractured zone. This observation, combined with the information from the drilling $\log$, that indicates a sudden drop of the drill string in correspondence of the fractured zones, allow us to infer that the fractures appear as 'gaps' of very limited thickness inside the igneous rock.

The log data shown in figures 2 and 3 are totally recorded in the granite rock whereas the well-log represented in figure 4 pertains both to the metamorphic basement (upper part) and the granitic intrusion (lower part). The contact between these two geological formations is located around $2780 \mathrm{~m}$ where a sudden density decrease is visible.

This $\log$ data $\left(V_{\mathrm{p}}, V_{\mathrm{s}}\right.$ and density) constitutes the input for building blocked models, downscaled to the seismic wavelength, that are then used to compute the AVA intercept and gradient. The well-log information we have available allows us to build 1D elastic and isotropic models only. The downscaling is performed making use of the Backus theory (Backus 1962, Schoenberg and Muir 1989, Folstad and Schoenberg 1992) that determines the elastic properties of an effective medium from the properties of the stack of layers. Assuming a peak frequency of the seismic signal of $20 \mathrm{~Hz}$ and considering a minimum $\mathrm{P}$-wave velocity of $4000 \mathrm{~m} \mathrm{~s}^{-1}$, the resulting equivalent layers have thickness of $20 \mathrm{~m}$.

Another approach that could be used to downscale the log values to the seismic wavelength is the O'Doherty-Anstey method, which takes into account the stratigraphic-filtering effects of the layers (O'Doherty and Anstey 1971). Both methods are discussed in detail by Stovas and Arntsen (2006).

As an example, figures 5( $a$ ) and $(b)$ show close-ups near the fracture locations 1 and 2, respectively. The original logs are in cyan, while the red logs result from the Backus averaging, and the dotted red lines indicate the fracture locations. Note that the decreases of density, $V_{\mathrm{p}}$ and $V_{\mathrm{s}}$ still remain evident in the blocked logs but the actual values may differ from fracture to fracture. We think this is likely due to the occurrence of both open fractures and of fractures (partly) filled by fine particles or by re-mineralization.

Computing the intercept and gradient for each interface of the blocked models (by means of equations (2) and (3), respectively), we can observe (figure 6) that all the AVA responses of the top of the fractured levels map onto the IV AVA class (see the triangles in figure 6), having a negative intercept and a positive gradient. Therefore, in terms of seismic signal, they will show a negative polarity at zero offset and amplitudes, in absolute value, decreasing with increasing angle of incidence. Figure 6 also shows the responses of all the other interfaces of the blocked models (magenta dots).

Note that the intercept and gradient responses of the top of these geothermal reservoirs are different from the ones that often occur for many, gas-saturated, silicoclastic rocks, where the reflections exhibit negative polarities at short offsets but amplitudes that increase in absolute value with increasing angle of incidence, that is a typical class III AVA.

Class IV reflections pertinent to clastic rock gas reservoirs frequently occur when a porous sand is overlain by a highvelocity unit (Castagna et al 1998), such as hard shales (e.g. siliceous or calcareous), or siltstones, or limestones and the contact between the hard rock seal and the porous reservoir is characterized by a decrease of both $V_{\mathrm{p}}$ and $V_{\mathrm{s}}$. This decrease of compressional and shear velocity, as well as of density, is also present in our case, where a localized fractured zone is encased in a tight igneous rock.

To better understand this behaviour we refer to the original Richards and Frasier (1976) approximation (equation (4)) as given in Aki and Richards (1980), and we decompose the AVA response of the equivalent layers containing the fractures, into three terms due to changes in $V_{\mathrm{p}}, V_{\mathrm{s}}$ and density, respectively.

This decomposition (figures $7(a)$ and $(b)$ ) for fractures 1 and 2 makes clear that, at normal incidence (where only the $V_{\mathrm{p}}$ and the density contrasts play a role in determining the response), the negative sign of the intercept is the result 


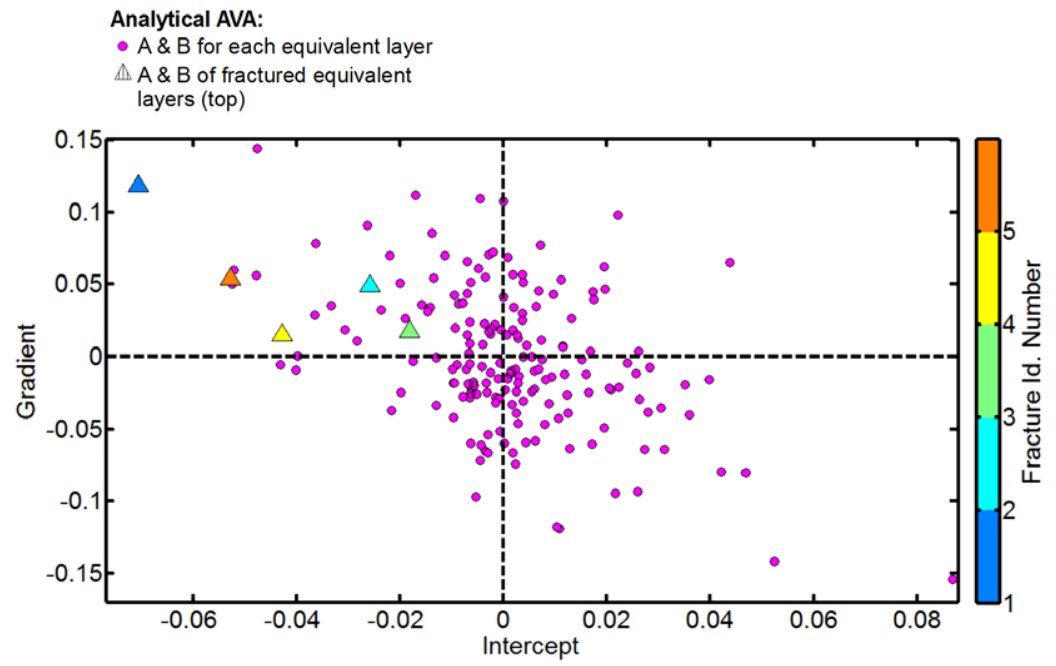

Figure 6. Intercept-gradient cross-plot of the reflection coefficients computed analytically for all the interfaces of the blocked models of the three wells (small magenta circles). The small triangles represent intercept and gradient pertaining to the top of the equivalent fractured layers.
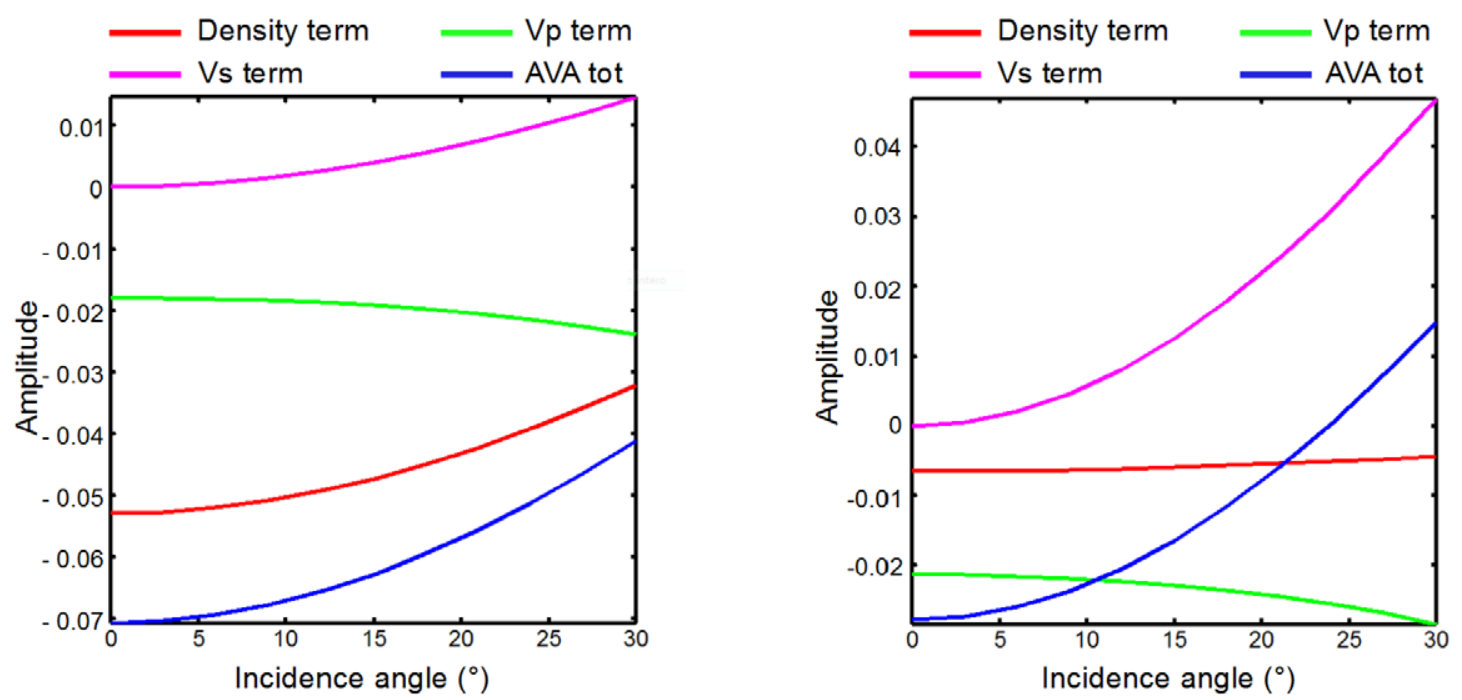

Figure 7. Reflection coefficients (blue curve) extracted from the blocked models for the top interface of the fractures 1 and $2((a)$ and (b), respectively) and their decomposition into the three terms (density and velocities contrasts) using the Richards and Frasier (1976) approximation.

of the decrease of both $V_{\mathrm{p}}$ and density. With increasing angle, the key parameter is the $V_{\mathrm{s}}$ contrast across the reflecting interface. In our case the $\Delta V_{\mathrm{s}}$ is negative and then its contribution becomes more positive with increasing angle. Therefore the net result is a small decrease in the absolute value of the reflection coefficient with increasing angle, thereby resulting in a class IV response having a positive gradient and a negative intercept.

As mentioned above, the linearization that brings to the Shuey equation assumes small incidence angles (less than $30^{\circ}$ ), but also small perturbations in velocity and density at the reflecting interface. In this case we are dealing with a complex system of interconnected fractures of limited space extension and with physical properties often sharply contrasting with the surrounding rocks, as shown in figures 2, 3 and 4. Moreover, the previous 'analytical' approach does not take into account the effects of wave propagation such as multiple reflections, interference and converted waves.

Therefore, it is advisable to check if the outcomes of this simple 'analytical' approach match with the results of a more stringent test. To this end, on the blocked models of the three wells of figures 2, 3 and 4, we generate synthetic seismograms by means of the reflectivity method (Kennett 1983) and we measure the AVA of reflections generated by the five fractured levels. We call this approach 'experimental'.

\section{5. 'Experimental' AVA responses of the fractured levels}

Figures 8, 9 and 10 show the synthetic CMPs of 100 traces each, with trace interval and minimum source to receiver 


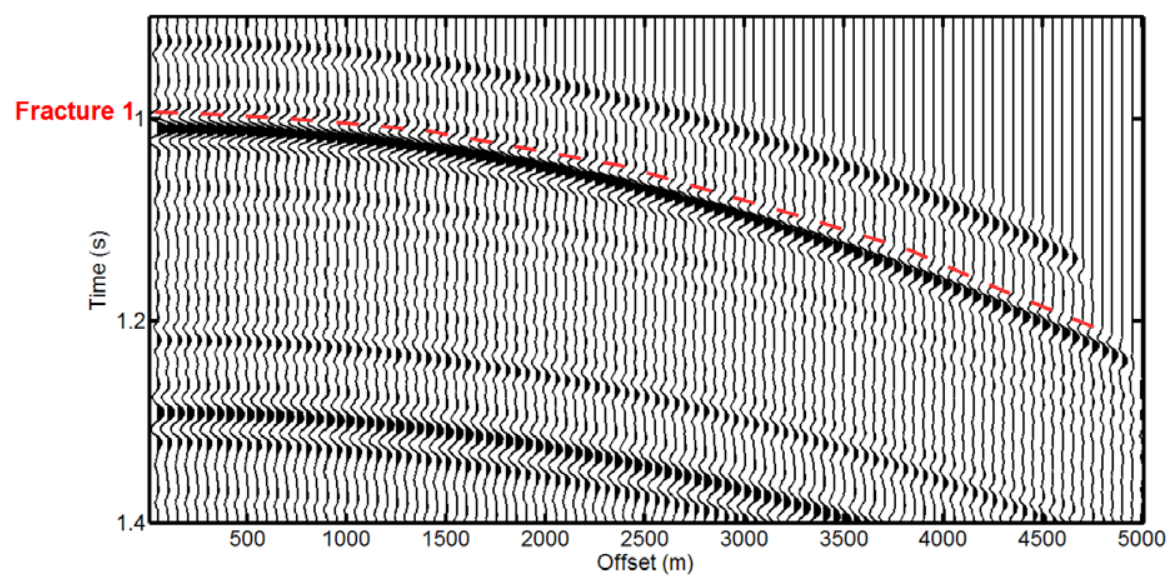

Figure 8. Synthetic CMP gather computed via the reflectivity method on the blocked model of well 1 . The dashed red line indicates the time position of the top of fracture 1 equivalent layer.

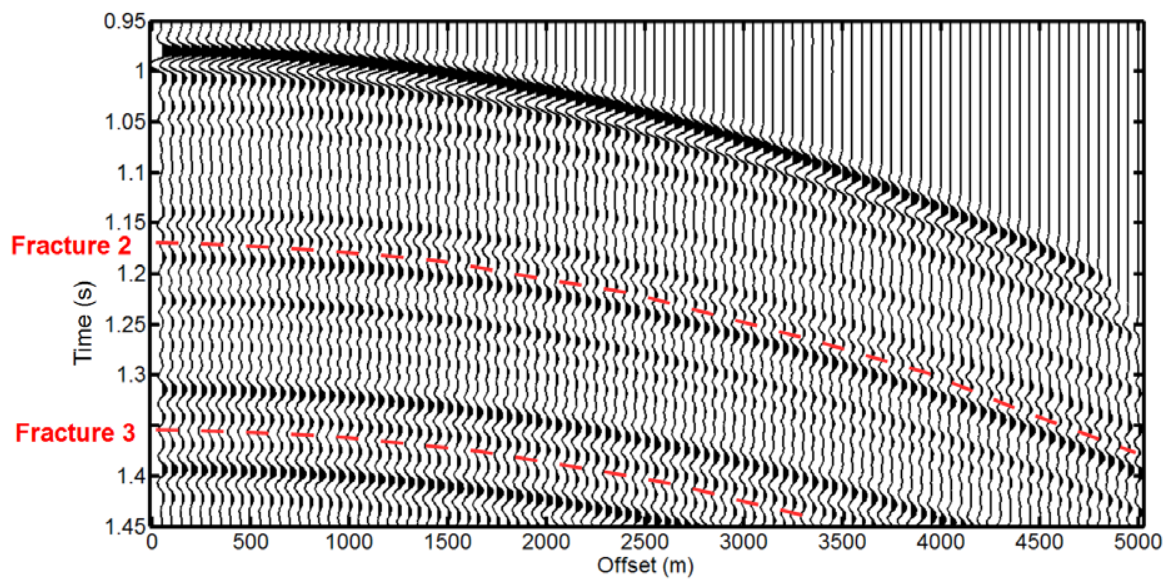

Figure 9. Synthetic CMP gather computed via the reflectivity method on the blocked model of well 2 . The dashed red lines indicate the time position of the top of the fractures 2 and 3 equivalent layers.

offset of $50 \mathrm{~m}$, in the time windows that correspond to the respective depth intervals of the models in figures 2,3 and 4.

After correcting for geometrical spreading effects and applying NMO correction, we extract the AVA intercept and gradient for each time sample of the synthetic gathers via least-squares regression.

To allow a proper comparison between intercept and gradient computed analytically from the blocked models and those extracted from the synthetic data, their values have been properly normalized and then plotted together as shown in figure 11.

The intercept-gradient cross-plots of the 'analytical' and the 'experimental' AVA (figure 11) show distributions of points that nicely overlaps. In particular, note the fair matching between the 'analytical' and the 'experimental' responses from the top of the five fractured levels (triangles and little squares, respectively). The observed differences can be mainly ascribed to the limited resolution of the synthetic wavelet, that causes interference effects, and to the presence of multiple and converted waves on the reflectivity seismograms. However, the 'experimental' responses confirm that the five fractured levels give rise to a class IV AVA as previously indicated by the 'analytical' data. Following the relationship presented in Castagna et al (1998), the background trend is indicated by a dotted red line. The background trend is calculated for a constant $V_{\mathrm{p}} / V_{\mathrm{s}}$ of 1.8 (that is the average value as indicated by the well-logs) and assuming that the average density does not vary with depth.

As is usually known for classical silicoclastic rocks (Ross 2000), the further a reflection lies from the background trend the more likely it can belong to a gas-sand level. This characteristic permits to pinpoint possible gas-sand reflections just observing the intercept-gradient cross-plot.

Conversely, in our case the intercept and gradient pertaining to the fractured levels lie very close to the background trend and it would not be possible to identify them as anomalies likely due to fractures. This difference with gas-sand exploration makes it clear we need to seek for a more effective attribute to point out the reflections from the deep fractured geothermal reservoirs.

\section{A possible indicator for fracture detection}

The decrease of density, $V_{\mathrm{p}}$ and $V_{\mathrm{s}}$ which occurs passing from the tight rock to the fractured levels causes the decrease of $\mathrm{P}$ and $\mathrm{S}$ reflection coefficients $\left(R_{\mathrm{p}}\right.$ and $\left.R_{\mathrm{S}}\right)$ too (see as an example $R_{\mathrm{p}}$ and $R_{\mathrm{S}}$ for fractures 1 and 2 in figure 12 ). 


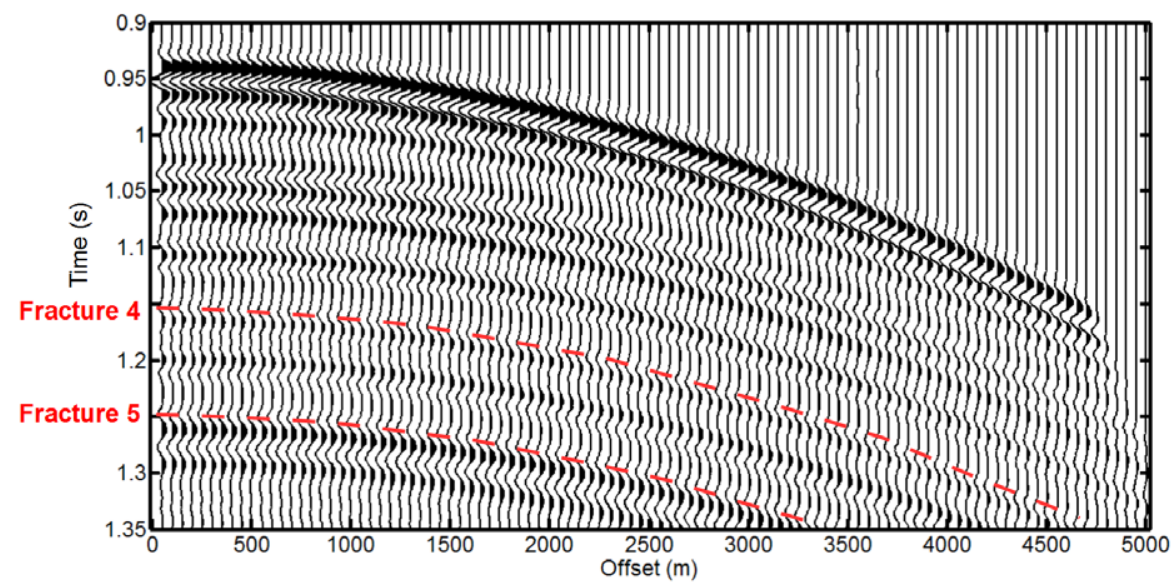

Figure 10. Synthetic CMP gather computed via the reflectivity method on the blocked model of well 3 . The dashed red lines indicate the time position of the top of the fractures 4 and 5 equivalent layers.

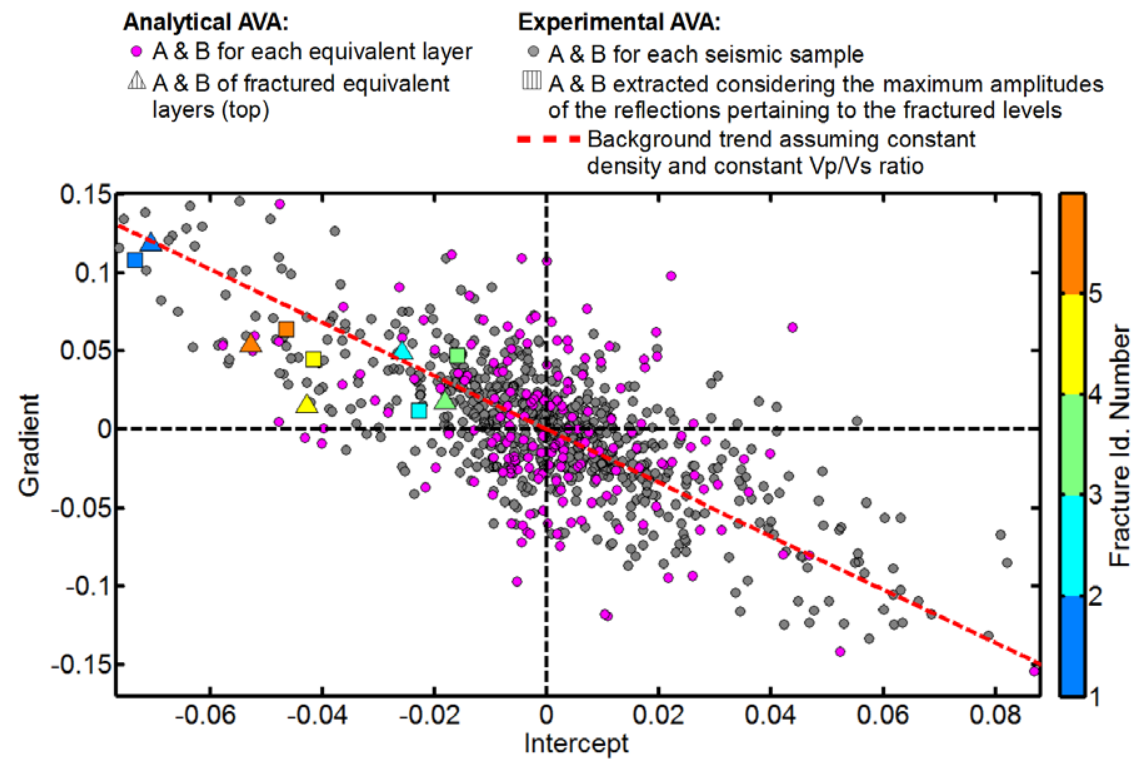

Figure 11. Intercept-gradient cross-plot of the reflection coefficients computed analytically for all the interfaces of the blocked models (small magenta circles, as in the previous figure 6) and of the (scaled) amplitudes versus angle of the synthetic reflections (small grey circles). The small triangles map the 'analytical' response while the small squares refer to the 'experimental' response of the top of the fractured levels. The colour bar codes the fracture number. Note the fair overlapping of the 'analytical' and of the 'experimental' responses and the proximity of points (triangles and squares) pertaining to the ('analytical' and 'experimental') responses of the fractured levels. Considering the reflections pertaining to the fractured zones we show the intercept and gradient values pertaining to the peak amplitude of the wavelets. The dotted red line shows the theoretical 'fluid line' assuming constant density and a constant $V_{\mathrm{p}} / V_{\mathrm{s}}$ of 1.8 .

For this reason, the $R_{\mathrm{p}}-R_{\mathrm{s}}$ indicator of equation (5), does not show any anomalous behaviour in our case. However, summing the two coefficients $\left(R_{\mathrm{p}}+R_{\mathrm{s}}\right)$ instead of differentiating them introduces a new attribute that is more suited to detect the fractured levels. With this new attribute, the fracture levels show up as samples with anomalous negative values compared to the background trend (figure 13). The $R_{\mathrm{p}}+R_{\mathrm{S}}$ attribute can be easily derived as follows:

$$
R_{\mathrm{p}}=\frac{1}{2}\left(\frac{\Delta V_{\mathrm{p}}}{\bar{V}_{\mathrm{p}}}+\frac{\Delta \rho}{\bar{\rho}}\right)=A
$$

is the P-wave reflection coefficient at normal incidence, i.e. the intercept $A$ as given in equation (2); the $\mathrm{S}$-wave reflection coefficient at normal incidence, assuming $V_{\mathrm{p}} / V_{\mathrm{s}}=2$ is given by (Castagna et al 1998)

$$
R_{\mathrm{s}}=\frac{1}{2}\left(\frac{\Delta V_{\mathrm{s}}}{\bar{V}_{\mathrm{p}}}+\frac{\Delta \rho}{\bar{\rho}}\right)=\frac{(A-B)}{2}
$$

and then

$$
\begin{aligned}
R_{\mathrm{p}}+R_{\mathrm{s}} & =\frac{1}{2}\left(\frac{\Delta V_{\mathrm{p}}}{\bar{V}_{\mathrm{p}}}+\frac{\Delta V_{\mathrm{s}}}{\overline{V_{\mathrm{s}}}}+\frac{2 \Delta \rho}{\bar{\rho}}\right)=A+\frac{(A-B)}{2} \\
& =\frac{(3 A-B)}{2} .
\end{aligned}
$$

Note, however, that equation (7) is verified only if $V_{\mathrm{p}} / V_{\mathrm{s}}=2$, which is common for sand-shale lithologies. Instead, in our 

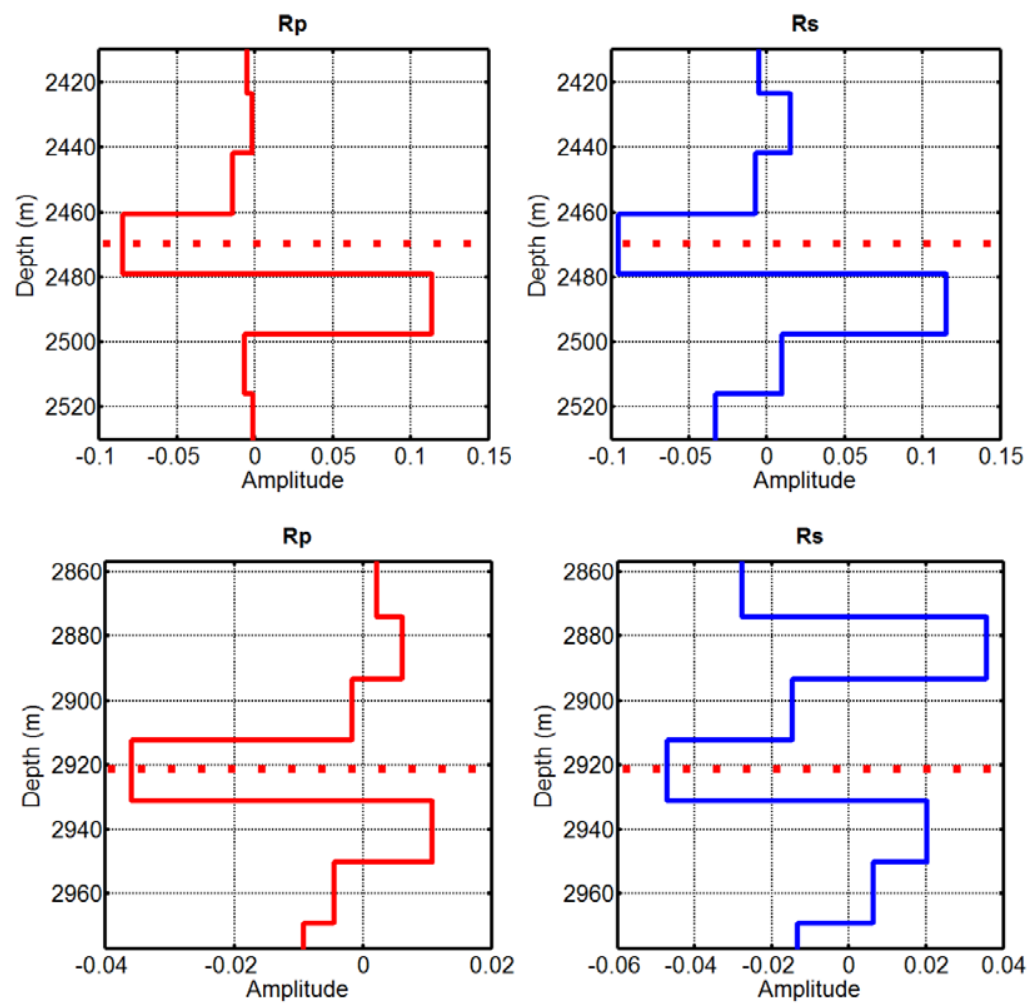

Figure 12. Examples of $R_{\mathrm{p}}$ and $R_{\mathrm{S}}$ coefficients for the interfaces of the blocked models in the vicinity of fracture $1((a)$, left side) and of fracture $2\left((b)\right.$, right side). The dotted black lines indicate the fracture positions. Note the decrease of both $R_{\mathrm{p}}$ and $R_{\mathrm{S}}$ in coincidence with the fractured levels.

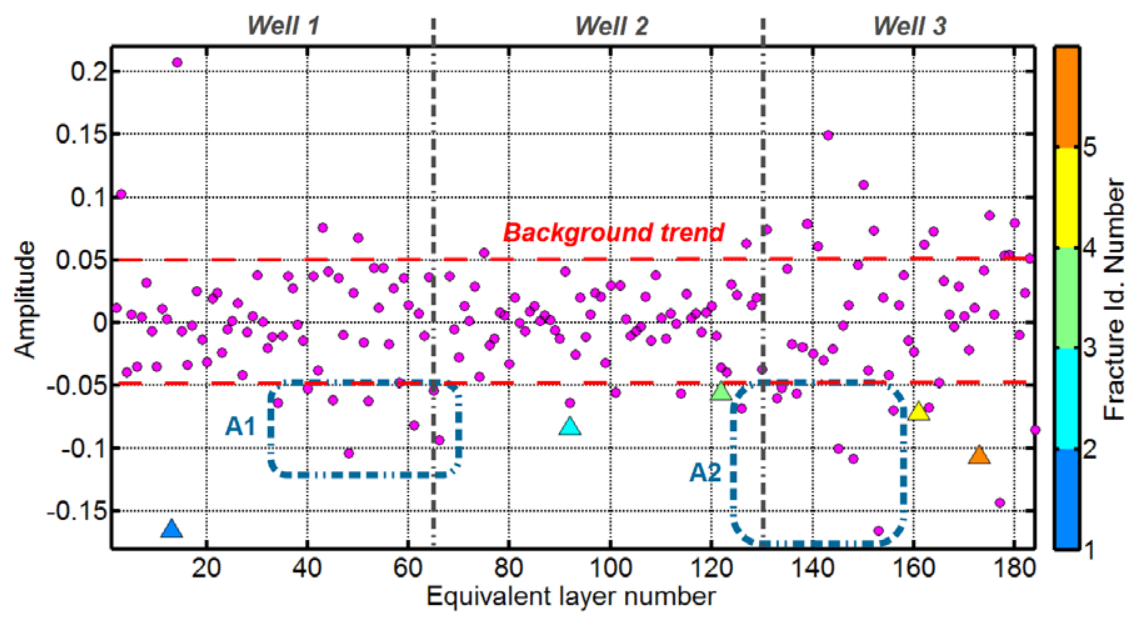

Figure 13. Plot of the $R_{\mathrm{p}}+R_{\mathrm{S}}$ coefficients computed analytically for all the interfaces of the blocked models (small magenta circles). The small triangles indicate the 'analytical' $R_{\mathrm{p}}+R_{\mathrm{S}}$ of the top of the fractured levels. The colour bar codes the fracture number. Note that $R_{\mathrm{p}}+R_{\mathrm{S}}$ samples pertaining to fractures tend to separate from the background (defined approximately by the two dashed horizontal red lines). The $R_{\mathrm{p}}+R_{\mathrm{S}}$ coefficients included in the blue rectangles $\mathrm{A} 1$ and $\mathrm{A} 2$ may pertain to other fractured zones along the well profiles.

case the average $V_{\mathrm{p}} / V_{\mathrm{s}}$ is around 1.8. Nevertheless, the true values of $R_{\mathrm{p}}+R_{\mathrm{s}}$, computed from the velocities and densities given by the well-logs, are very close to those estimated via equation (7) assuming $V_{\mathrm{p}} / V_{\mathrm{s}}=2$, and thus, from a practical point of view, this approximation holds.

In figures 13 and 14 we show the values of $R_{\mathrm{p}}+R_{\mathrm{S}}$ computed for each interface of the blocked model ('analytical' AVA) and for each seismic sample ('experimental' AVA), respectively.
These figures show that most samples lie between 0.05 and -0.05 , a range we may define as the 'background' trend, against which all the analysed fracture reflections stand out, showing strong negative values (small triangles in figure 13, and small squares in figure 14).

Moreover, two additional anomalous zones, labelled A1 and A2 in figure 13 and E1 and E2 in figure 14 (enclosed by the dotted blue rectangles) are visible in the data. These zones 


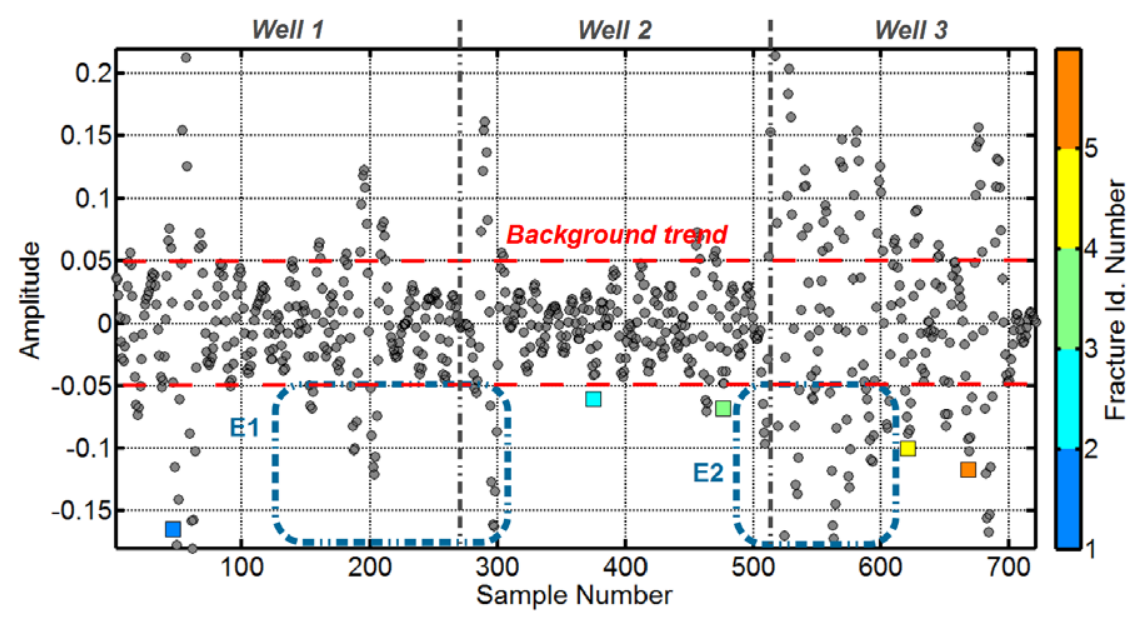

Figure 14. Plot of the $R_{\mathrm{p}}+R_{\mathrm{S}}$ coefficients derived from the sample by sample AVA intercept and gradient of the synthetic reflections computed on the blocked models (small grey circles). The little squares indicate the 'experimental' $R_{\mathrm{p}}+R_{\mathrm{s}}$ pertinent to the fractured levels. The colour bar codes the fracture number. As noted for the 'analytical' response in the previous figure, the $R_{\mathrm{p}}+R_{\mathrm{S}}$ points pertaining to fractures tend to separate from the background. In this case too, two areas indicated by the blue rectangles E1 and E2, that correspond to the same levels within the rectangles $\mathrm{A} 1$ and $\mathrm{A} 2$ of the previous figure, contain $R_{\mathrm{p}}+R_{\mathrm{s}}$ coefficients that may pertain to other fractured zones along the well profiles.

represent corresponding depth and time intervals for the 'analytical' and the 'experimental' responses respectively. These samples show values of $R_{\mathrm{p}}+R_{\mathrm{s}}$ as low as those pertaining to the already discovered fractured intervals and might indicate the presence of other fractured levels.

\section{Conclusions}

The deepest geothermal reservoirs in the Larderello-Travale area are hosted in localized fractured zones within the intrusive basement. The fractured levels are characterized by a consistent decrease in density and seismic velocities compared to the density and velocities of the encasing tight rock. This is evident both in the actual well-logs and in the downscaled depth models.

However, despite the strong contrast at the reservoir interfaces, linear AVA theory can also be applied to this complex case, and the good match we observe between the 'analytical' and the 'experimental' responses further confirms the potential of the AVA analysis. Both the 'analytical' and the 'experimental' approaches indicate that the amplitude versus angle response of the fractured levels corresponds to a class IV AVA and thus it is different from the most common response for gas-sand reservoirs, that is a class III AVA. Moreover, differences with hydrocarbon exploration are not restricted to the different mapping in the AVA quadrants but, more importantly, are related to the fact that the AVA responses of the examined fractured zones do not show any significant deviation from the fluid line. Thus, a conventional, hydrocarbon suited, interpretation of the AVA attributes, such as $A \times B$ or $R_{\mathrm{p}}-R_{\mathrm{s}}$, would not be effective in this case.

The simultaneous and significant decrease at the top of the fractured levels of both the P-wave and the S-wave reflection coefficients suggest to use the sum of $R_{\mathrm{p}}$ and $R_{\mathrm{S}}$ as a more suitable indicator of the presence of fractures. This indicator can be easily derived combining intercept and gradient attributes.

In the examined cases, the reflections that pertain to the fractures show anomalous negative values of $R_{\mathrm{p}}+R_{\mathrm{s}}$ that clearly stand out from the background trend pertaining to all the other reflections. Thus, linear and isotropic AVA analysis may be an additional tool in the geothermal exploration of the intrusive basement in this area. Also, this study has detected the presence of other anomalous $R_{\mathrm{p}}+R_{\mathrm{S}}$ values that could be related to other fractured levels that were not previously detected, or indicated as relevant, due to their limited vapour production. We note that the outcomes of this feasibility study and all the above considerations are strictly valid for this specific area but it may also be possible that they can be extended to other exploration cases.

The proposed methodology awaits to be applied to real seismic data so as to test its true exploration potential. To this end, a major requirement is the availability of high quality pre-stack seismic data.

Finally, AVA tools such as those described above do not complete all the possible seismic reflection means for detecting fractured zones. There is a vast scientific literature showing that anisotropic wave propagation effects (such as shear wave splitting) and azimuthal dependence of reflection (such as AVAZ, amplitude versus azimuth analysis) are additional tools for this purpose. Their applicability to our specific exploration case in the igneous basement of the Larderello-Travale area could not be evaluated because the well information we had was not sufficient to develop specific and reliable anisotropic models for each fractured level. However, these methods to be applied require the availability of 3D seismic data with a fairly homogeneous distribution of source to receiver offsets, with a wide azimuthal range and with an excellent signal to noise ratio. These requirements can be hardly met in the LarderelloTravale area and thus simpler, more robust and less costly methods, such as the one we propose, can be more feasible. 


\section{Acknowledgments}

The authors wish to thank ENEL GreenPower for making available portions of the well-log data and for the permission to publish this paper.

\section{References}

Adriansyah A and McMechan G A 2001 AVA analysis and interpretation of a carbonate reservoir: northwest Java basin, Indonesia Geophysics $\mathbf{5 0} 744-54$

Aki K and Richards P G 1980 Quantitative Seismology: Theory and Methods (San Francisco, CA: W H Freeman)

Backus GE 1962 Long-wave elastic anisotropy produced by horizontal layering J. Geophys. Res. 67 4427-40

Barbier E 2002 Geothermal energy and current status: an overview Renew. Sustainable Energy Rev. 6 3-65

Batini F, Cameli GM, Lazzarotto A and Liotta D 2003 Line CROP 18: Southern Tuscany. Crop Atlas: seismic reflection profiles of the Italian crust Mem. Descr. Carta Geol. d'It. 62 137-44

Bertini G, Casini M, Ciulli B, Ciuffi S and Fiordelisi A 2005 Data revision and upgrading of the structural model of the Travale geothermal field (Italy) Proc. 2005 World Geothermal Congress (Antalya, Turkey, April 2005) pp 24-9

Bertini G, Casini M, Gianelli G and Pandeli E 2006 Geological structure of a long-living geothermal system Larderello, Italy Terra Nova 18 163-9

Carmignani L, Decandia F A, Disperati L, Fantozzi P L, Lazzarotto A, Liotta D and Oggiano G 1995 Relationships between the Sardinia-Corsica-Provençal domain and the northern Apennines Terra Nova 7 128-37

Carmignani L, Decandia F A, Fantozzi P L, Lazzarotto A, Liotta D and Meccheri M 1994 Tertiary extensional tectonics in Tuscany (Northern Apennines, Italy) Tectonophysics 238 295-315

Carmignani L and Kligfield R 1990 Crustal extension in the northern Apennines: the transition from compression to extension in the Alpi Apuane core complex Tectonics 9 1275-303

Casini M, Ciuffi S, Fiordelisi A, Mazzotti A, Perticone I, Spinelli E and Stucchi E 2009 3D seismic for the deep exploration of the Travale geothermal field (Italy): I-GET project results Geothermal Resources Council Annual Meeting (Davis, CA) pp 1035-9

Casini M, Ciuffi S, Fiordelisi A, Mazzotti A and Stucchi E 2010 Results of a 3D seismic survey at the Travale (Italy) test site Geothermics 39 4-12

Castagna J P 1993 Petrophysical imaging using AVA Leading Edge 12 172-9

Castagna J P and Smith A W 1994 Comparison of AVA indicators: a modelling study Geophysics 59 1849-55

Castagna J P and Swan H W 1997 Principles of AVA crossplotting Leading Edge 16 337-42

Castagna J P, Swan H W and Foster D J 1998 Framework for AVA gradient and intercept interpretation Geophysics 63 948-56
Fatti J L, Smith G C, Vail P J, Strauss P J and Levitt P R 1994 Detection of gas in sandstone reservoirs using AVA analysis: a 3D seismic case history using the Geostack technique Geophysics 59 1362-76

Folstad P G and Schoenberg M 1992 Use of equivalent anisotropic medium theory to calculate synthetic AVA response $S E G$ / EAGE Workshop (Big Sky, MT) pp 614-21

Jolivet L, Dubois R, Fournier R, Goffè B, Michard A and Jourdan C 1990 Ductile extension in alpine Corsica Geology 18 1007-10

Jolivet L et al 1998 Mid-crustal shear zones in postorogenic extension: example from the Northern Tyrrhenian Sea J. Geophys. Res. 103 12123-60

Kennett B L N 1983 Seismic Wave Propagation in Stratified Media (Cambridge: Cambridge University Press)

Mazzotti A 1990 Prestack amplitude analysis methodology and application to seismic bright spots in the Po Valley, Italy Geophysics 55 157-66

Mazzotti A 1991 Amplitude, phase and frequency versus offset applications Geophys. Prospecting 39 863-86

Mazzotti A, Zamboni E, Stucchi E and Ciuffi S 2002 Seismic characterisation of geothermal reservoirs - a case study in western Tuscany, Italy 64th EAGE Conf. and Technical Exhibition (Florence, Italy) extended abstract C037

O'Doherty R F and Anstey N A 1971 Reflections on amplitudes Geophys. Prospecting 19 430-58

Ostrander W J 1984 Plane-wave reflection coefficients for gas sands at non-normal angles of incidence Geophysics 49 1637-48

Richards P G and Frasier C W 1976 Scattering of elastic wave from depth-dependent inhomogeneities Geophysics 41 441-58

Ross C P 2000 Effective AVA crossplot modeling: a tutorial Geophysics 65 700-11

Ross C P 2002 Quantifying AVO attributes and their effectiveness Leading Edge 21244

Ross C P and Sparlin M A 2000 Improved crossplot analysis using visualization techniques Leading Edge 19 1188-99

Rutherford S R and Williams R H 1989 Amplitude versus-offset variations in gas sands Geophysics $\mathbf{5 4} 680-8$

Schoenberg M and Muir F 1989 A calculus for finely layered anisotropic media Geophysics 54 581-9

Shen F, Sierra J, Burns D R and Toksöz M N 2002 Azimuthal offset-dependent attributes applied to fracture detection in a carbonate reservoir Geophysics 67 355-64

Shuey R T 1985 A simplification of the Zoeppritz equations Geophysics $\mathbf{5 0}$ 609-14

Smith G C and Gidlow P M 1987 Weighted stacking for rock property estimation and gas detection Geophys. Prospecting 35 993-1014

Stovas A and Arntsen B 2006 Vertical propagation of low-frequency waves in finely layered media Geophysics 71 T87-94

Ursenbach C P and Stewart R R 2008 Two-term AVO inversion: equivalences and new methods Geophysics 73 C31-8

Wiggins R, Kenny G S and McClure C D 1983 A method for determining and displaying the shear-velocity reflectivities of a geologic formation European Patent Application 0113944

Wang Y 1999 Approximations to the Zoeppritz equations and their use in AVO analysis Geophysics 64 1920-7

Zoeppritz K 1919 On the reflection and propogation of seismic waves Gottinger Nachrichten I 66-84 